\title{
Comparison of Two Methods for Monitoring Population Indices of Small Mammals on Seasonal Islands
}

POROWNANIE DWOCH METOD OCENY WSKAZNIKOW POPULACYJNYCH U MAEYCH SSAKOW ZAMIESZKUJĄCYCH SEZONOWE WYSPY

\author{
Richard M. POCHÉ \& MD. Yousuf MIAN
}

\begin{abstract}
Poché R. M. \& Mian MD. Y., 1985: Comparison of two methods for monitoring population indices of small mammals on seasonal islands. Acta theriol., 30, 8: 161-165 [With 3 Tables]

During summer monsoon rains in Bangladesh, many small villages are surrounded by flood waters and become seasonal islands. As part of a larger study, snap-traps and tracking tiles were compared as means of monitoring small mammal relative abundance in the villages. Traps and tiles were set for two successive nights each week over a 20 week period. The results showed no significant difference between Day 1 and Day 2 data for each technique. The method selected for long-term population monitoring should be based on the objectives of the study and whether a removal or non-removal system should be employed.

[Bangladesh Agricultural Research Institute, Vertebrate Pest Section, Joydebpur, Banglades'h].
\end{abstract}

\section{INTRODUCTION}

Many techniques have been used within the past 30 years to study field rodent numbers. A thorough review was presented by Smith et al. (1975). The most common means of obtaining information on animal abundance is through the use of traplines, generally consisting of $10-100$ traps set in a straight line (Southern, 1965; Tamarin, 1977; West et al., 1976). The trapline method, known as a removal technique, has been used to estimate population numbers (Hayne, 1949; Zippin, 1958). A variety of trapping configurations have been tested (Smith et al., 1975) but as Stickel (1948) stated, the method may not be fully reliable in estimating numbers, but should be used primarily for convenience (as an index) and is generally one of the least expensive methods.

Apart from the use of traps to assess population levels, techniques involving animal signs such as droppings, footprints, runways, or burrows have been used. Such a nonremoval technique was described by Lord et al. (1970) and involved coating plastic floor tiles with ink and examining each the following morning for rat tracks. The results produced an index of rodent activity or relative abundance. Marten (1972) rated the technique superior to traplines.

In Bangladesh deepwater rice is sown in March or April, depending on the initiation of rainfall. During the floods, rats emigrate fields to nearby villages which become small, distinct islands. When the floating rice stems provide enough buoyancy, rats swim out onto the rice to cut and feed on stem hearths.

${ }^{1}$ Denver Wildlife Research Center, U.S. Fish and Wildlife Service, Bldg. 16, Federal Center, Denver. CO. Present address: Lipha Chemicals Inc., Chempar Products Division, 660 Madison Avenue, New York, NY 10021 USA. 
As part of a Bangladesh Agricultural Research Institute long-term study of rodents in deepwater rice, an important component of the program was to monitor monthly and annual fluctuations in rodent numbers. Since live-trapping is too time-consuming and expensive, a study similar to the one by West et al. (1976) conducted in the Philippines was organized. A field test was designed to (1) compare the use of tracking tiles vs. snap traps on islands in deepwater rice, and (2) determines if only 1 night of trapping or the use of tiles was sufficient to monitor the relative abundance of small mammals.

\section{METHODS}

The study area was located approximately $10 \mathrm{~km}$ WSW of Dacca, Bangladesh in a typical deepwater rice growing delta near the village of Agrakhola. The region floods seasonally from late June to early November.

One island (approximately 2.5 ha in size) was selected and small mammal activity monitored. The study was conducted between 6 September 1979 and 23 February 1980. For 2 consecutive nights each week, over the 20 -week period, 50 snap traps (Victor 4 -way ${ }^{1}$ ) and $50,25 \times 25-\mathrm{cm}$ vinyl tiles were placed on the island shortly after dusk. Twenty tiles and traps each were set in dwellings, 10 between dwellings, and 20 along the island periphery. Coconut was used as bait for the traps.

The total number of traps sprung was also tallied. This included rodent captures, shrew captures, and empty but sprung traps.

One-half of each gray-colored tile was smeared with mimeograph ink and the tile examined on the following day for tracks. Several drops of mustard oil, to prevent drying, were mixed in with about $0.5 \mathrm{~cm}^{3}$ of ink. The number of tiles with tracks was recorded. After examination of the tiles on the following day, acetone and cotton were used to remove tracks from the uninked portion.

Paired $t$-tests were used to examine for differences between data collected during Day 1 and Day 2 for tiles, traps, and sprung traps. The coefficient of variation was determined for each technique used. The mean data for 2 nights over the 20 -week study period for each techniques were compared using analysis of variance.

\section{RESULTS AND DISCUSSION}

Rodent species collected from the study island included the lesser bandicoot rat Bandicota bengalensis Gray, the greater bandicoot rat $B$. indica Bechstein, the roof rat Rattus rattus Linnaeus, and the house mouse Mus musculus Linnaeus. In addition, an Insectivora, the musk shrew Suncus murinus Linnaeus was common on the island.

Results from this study are presented in Tables 1 and 2. The study enabled an examination of a removal vs. a nonremoval technique of population index assessment. A t-test for each group of data, for trapping, tiles, and total sprung traps, showed no significant differences between Day 1 and Day 2 for each technique.

The coefficient of variation was lowest in the total sprung trap data, a possibility speculated by West et al. (1976). Most variability was shown in the use of snap traps (Table 3). The ANOVA results indicated significant differences between the three techniques $(P<0.005, F=31.8)$.

${ }^{1}$ Use of trade mark does not imply endorsement by agencies of the Bangladesh or U.S. Governments. 
Significant differences $(P<0.005)$ were observed between the tile and trap data. Weather conditions, moonlight, and possible trap shyness over the 20-week period contributed to higher variability in trap success. We assumed that the vinyl tiles did not affect small mammal movements nor activity.

The removal trapping data showed no significant differences $(P<0.05)$ between days. Over the duration of the study, the mean trap success for Day 1 was 1.8 rats and 1.75 for the second day, indicating little impact on the local population from the previous night's trapping.

Table 1

Summary of data collected from an experimental island in which 50 snap trap and 50 tracking tiles were set for two $(1,2)$ consecutive nights each week over a 20 -week period.

\begin{tabular}{|c|c|c|c|c|c|c|}
\hline \multirow[t]{2}{*}{ Week } & \multicolumn{2}{|c|}{ Titles tracked } & \multicolumn{2}{|c|}{ Mammals trapped } & \multicolumn{2}{|c|}{ Traps sprung } \\
\hline & 1 & 2 & 1 & 2 & 1 & 2 \\
\hline 1 & 6 & 3 & 2 & 4 & 6 & 9 \\
\hline 2 & 0 & 0 & 1 & 2 & 5 & 8 \\
\hline 3 & 6 & 8 & 3 & 2 & 7 & 5 \\
\hline 4 & 6 & 8 & 3 & 3 & 6 & 6 \\
\hline 5 & 4 & 3 & 2 & 2 & 7 & 5 \\
\hline 6 & 3 & 2 & 2 & 2 & 6 & 5 \\
\hline 7 & 2 & 1 & 1 & 1 & 3 & 4 \\
\hline 8 & 2 & 2 & 0 & 0 & 2 & 3 \\
\hline 9 & 4 & 3 & 0 & 0 & 3 & 4 \\
\hline 10 & 3 & 4 & 2 & 1 & 4 & 4 \\
\hline 11 & 2 & 4 & 1 & 1 & 4 & 5 \\
\hline 12 & 4 & 2 & 2 & 1 & 6 & 5 \\
\hline 13 & 2 & 3 & 4 & 2 & 8 & 6 \\
\hline 14 & 2 & 3 & 2 & 1 & 7 & 4 \\
\hline 15 & 4 & 2 & 2 & 0 & 4 & 3 \\
\hline 16 & 2 & 3 & 1 & 0 & 4 & 3 \\
\hline 17 & 3 & 4 & 2 & 2 & 6 & 5 \\
\hline 18 & 4 & 3 & 2 & 2 & 6 & 8 \\
\hline 19 & 3 & 4 & 2 & 3 & 6 & 4 \\
\hline 20 & 4 & 3 & 2 & 6 & 2 & 10 \\
\hline
\end{tabular}

Table 2

Summary data for comparative study of techniques in monitoring small mammal relative abundance over a 20 -week period.

\begin{tabular}{|c|c|c|c|c|c|c|c|}
\hline Day & Mean & $\mathrm{SD}$ & CV. $\%$ & $\begin{array}{l}\text { Mean for } \\
2 \text { nites }\end{array}$ & $\begin{array}{l}\mathrm{SD} \text { for } \\
2 \text { nites }\end{array}$ & $\begin{array}{c}\mathrm{CV} \text { for } \\
2 \text { nites } \%\end{array}$ & $t$-values \\
\hline \multicolumn{8}{|c|}{ Tiles tracked } \\
\hline $\begin{array}{l}1 \\
2\end{array}$ & $\begin{array}{l}3.3 \\
3.25\end{array}$ & $\begin{array}{l}1.559 \\
1.916\end{array}$ & $\begin{array}{l}47 \\
59\end{array}$ & 3.275 & 2.387 & 48 & $0.1523^{\text {ns }}$ \\
\hline \multicolumn{8}{|c|}{ Mammals trapped } \\
\hline $\begin{array}{l}1 \\
2\end{array}$ & $\begin{array}{l}1.8 \\
1.75\end{array}$ & $\begin{array}{l}0.951 \\
1.482\end{array}$ & $\begin{array}{l}53 \\
85\end{array}$ & 1.775 & 1.045 & 59 & $0.1649^{\text {ns }}$ \\
\hline \multicolumn{8}{|c|}{ Traps sprung } \\
\hline $\begin{array}{l}1 \\
2\end{array}$ & $\begin{array}{l}5.35 \\
5.3\end{array}$ & $\begin{array}{l}1.631 \\
2.003\end{array}$ & $\begin{array}{l}30 \\
38\end{array}$ & 5.325 & 1.575 & 30 & $0.1209^{\text {ns }}$ \\
\hline
\end{tabular}


The greater bandicoot rat, weighing to $1 \mathrm{~kg}$, is common in the area, and was collected from the experiment study area. We speculate that many of the sprung traps were tripped by the large rodent, since it was infrequently captured in the snap traps.

The results of this study indicated that 1 night of trapping or the use of tracking tiles is sufficient in long-term studies to monitor small mammal relative abundance on islands in the deepwater rice zone of Bangladesh. The choice of method depends upon the purpose of the study. If trends in rodent or small mammal numbers are required, as in bait efficacy trial, the use of tracking tiles may be preferred. One drawback in using tiles is that it becomes difficult at times to differentiate between shrew and rodent footprints. The field mouse (Mus booduga) was trapped on adjacent islands and discerning between $M$. booduga and $M$. musculus based on tracks may be difficult. The roof rat and lesser bandicoot rat have similar-size hind feet. Therefore, information relative.

\section{Table 3}

Comparison of snap traps and inked tracking tiles for monitoring small mammal abundance on 2 consecutive nights each week during 20 weeks in 1980 in the deepwater rice zone of Bangladesh.

\begin{tabular}{ccccc}
\hline Method & Night & Mean & SD & CV, \% \\
\hline Tiles tracked & 1 & 3.30 & 1.56 & 47 \\
& 2 & 3.25 & 1.92 & 59 \\
& Avg & 3.28 & 2.39 & 48 \\
\hline Mammals trapped & 1 & 1.80 & 0.95 & 53 \\
& 2 & 1.75 & 1.48 & 85 \\
& Avg & 1.80 & 1.05 & 59 \\
\hline \multirow{2}{*}{ Traps sprung } & 1 & 5.35 & 1.63 & 30 \\
& 2 & 5.30 & 2.00 & 38 \\
& Avg & 5.33 & 1.58 & 30 \\
\hline
\end{tabular}

to species composition may be misleading. Tracking tiles may be used for bait efficacy field trials, since there is less variability in monitoring activity trends.

If accurate data on species composition, sex ratio, and reproductive parameters are required, the use of snap traps would be most effective. Selecting live or kill traps for a study depends on the objectives. If no trap mortality on the rodent fauna (nonremoval method) is desired, live traps may be preferable.

Most of the island villages in southern Bangladesh are similar in size. We, therefore, feel the data obtained in this study are reliable and reflect approaches to consider in monitoring rodent populations in the unique agrosystem. Ideally, it would have been better had the experiment been conducted on more than one island. Access and transport of equipment through the deepwater rice and between islands, with water to $4 \mathrm{~m}$ deep, was difficult. The lengthy time required to set traps and tiles on one island, then to move to another, limited our activity, since 
the equipment was set out after sunset to avoid human and domestic animal interference. We felt that although replicate islands would have enhanced the study, the subsequet bias of our later evening activity in setting tiles and traps would inject much bias by possibly affecting rodent and shrew movement patterns.

Acknowlegdements: We thank Daniel Thompson (Denver Wildlife Research Center) for reviewing this manuscript. This study was financially supported by the Bangladesh Agricultural Research Institute and the United States Agency for International Development under the project "Agricultural Research Vertebrate Pest Component" PASA ID/BNG-0003-1-78.

\title{
REFERENCES
}

Hayne D. W., 1949: Two methods for estimating population from trapping records. J. Mammal., 30: 399-411. - Lord R. D., Vilches A. M., Maiztegui J. I. \& Soldini C. A., 1970: The tracking board: a relative census technique for studying rodents. J. Mammal., 51: 828-829. - Marten G. G., 1972: Censusing mouse populations by means of tracking. Ecology, 53: 859-867. - Smith M. H., Gardner R. H., Gentry J. B., Kaufman D. W. \& O'Farrell M. H., 1975: Density estimations of small mammal populations. [In: "Small mammals: their productivity and population dynamics", F. B. Golley, K. Petrusewicz, L. Ryszkowski, eds.]. Cambridge Univ. Press: 25-53. London. - Southern H. N., 1965: The trapline index to small mammal populations. J. Zool. (London), 147: 217-221. - Stickel L. F., 1948: The trap line as a measure of small mammal populations. J. Wildl. Manage., 12: 153-161. - Tamarin R. H., 1977: Reproduction in the island beach vole, Microtus breweri, and the mainland meadow vole, Microtus pennsylvanicus, in southeastern Massachusetts. J. Mammal, 58: 536-548. - West R. R., Fall M. W. \& Benigno E. A., 1976: Comparison of tracking tiles and snap traps for obtaining population indices of Rattus rattus mindanensis in the Philippines. Philipp. Agric., 59: 379-386. Zippin C., 1958: The removal method of population estimation. J. Wildl. Manage., 22: $82-90$.

Accepted, October 4, 1984.

\section{Relative Capture Efficiency of Large and Small Sherman Live Traps}

WZGLEDDNA EFEKTYWNOSC MAEYCH I DUZYCH ŻYWOŁOWEK SHERMANA

\author{
Mark S. MALY \& Jack A. CRANFORD
}

Maly M. S. \& Cranford J. A., 1985: Relative capture efficiency of large and small Sherman live traps. Acta theriol., 30, 8: 165-167 [With 1 Table]

In a study of small mammal populations on Assateague Island, Virginia, U.S.A., two species (Microtus pennsylvanicus, Oryzomys palustris) exhibited a significant preference for large rather than small Sherman live traps. Three smaller species (Cryptotis parva, Mus musculus, Peromyscus leucopus) did not show a significant bias with 